\title{
Evaluation of hearing in middle-aged patients with diabetes mellitus type 2
}

\author{
Bijan Forogh ${ }^{1,2}$, Ronak Zeinolabedini ${ }^{3}$, Mahdi Akbari $^{3}$, Elaheh Mianehsaz $^{1 *}$ \\ ${ }^{1}$ Physical Medicine and Rehabilitation, Tehran University of Medical Sciences, Tehran, Iran \\ ${ }^{2}$ Brain and Spinal Cord Injury Repair Research Center, Tehran, Iran \\ ${ }^{3}$ Faculty of Rehabilitation Sciences, Tehran University of Medical Sciences, Tehran, Iran \\ Email: ${ }^{*}$ elaheh.mianehsaz@gmail.com
}

Received 2 March 2013; revised 5 April 2013; accepted 7 May 2013

Copyright (C) 2013 Bijan Forogh et al. This is an open access article distributed under the Creative Commons Attribution License, which permits unrestricted use, distribution, and reproduction in any medium, provided the original work is properly cited.

\begin{abstract}
Introduction: Involvement of auditory pathway is one of the examples of central neuropathy in diabetics. The purpose of this study is to compare the auditory function of patients with type 2 diabetes mellitus with healthy subjects. Methodology: 30 diabetic and 30 healthy subjects participated in this study. For all participants conventional pure-tone audiometry (PTA) and Auditory Brainstem Evoked Responses (ABER) study were performed. Results: In PTA Hearing threshold only at 2, 4, $8 \mathrm{KHz}$ frequencies were significantly higher than healthy subjects but were in normal range in patients with diabetes. ABER revealed that absolute latencies of waves I, III, $\mathrm{V}$ and inter wave latencies of III-V, I-V, I-III were significantly prolonged in diabetics. Conclusion: In this study, $50 \%$ of diabetic patients had hearing defects in ABER test despite normal hearing threshold and good metabolic control. Prolonged inter wave latencies of I-III, III-V, I-V explains retrocochlear and brain stem involvement.
\end{abstract}

Keywords: Diabetes; Auditory Brain Stem Evoked Responses; Hearing Impairment

\section{INTRODUCTION}

Diabetes mellitus is a common metabolic disease characterized by hyperglycemia with or without glycosuria. Its three common microvascular complications are neuropathy, retinopathy and nephropathy. Peripheral and autonomic neuropathy are more popular than central neuropathy which was considered for the first time in 1965 [1]. The involvement of auditory pathway is a shining example of central neuropathy. Previous reports in the field of hearing loss in diabetic patients have given

\footnotetext{
${ }^{*}$ Corresponding author.
}

conflicting results. On the one hand, several reports have shown a bilateral sensorineural hearing loss affecting mainly the high and middle frequencies in patients with diabetes mellitus, being characteristic of presbycusis [2]; on the other hand, some other studies have not reported any disorder in the hearing threshold of diabetics in Pure Tone Audiometry (PTA) test $[3,4]$. Auditory Brainstem Evoked Responses (ABER) is used to evaluate the performance of the auditory pathway from inner ear to upper brainstem having seven waves in ABER (I to VII); however, only waves I, III ,and V are recorded reliably enough to be routinely used in clinical applications. The waves I to VII originate from the eighth nerve, cochlear nucleus, superior olivary complex, mid and upper pons, upper pons, and lower mid brain respectively. The origins of waves VI and VII are medial geniculate bodies and auditory radiations [5]. ABER was initially applied to evaluate auditory function in diabetes mellitus type 1 in 1981 [6]. The most common abnormality of Auditory Brainstem Evoked Responses is the lengthening of the latency of waves III and V [7]. However, in some studies there have been no significant differences in ABER results among diabetics and healthy people [8]. ABER disorders are more frequent in diabetic patients affected with other micro vascular complications such as retinopathy, nephropathy, and peripheral sensori-motor polyneuropathy [9]. Consequently, the purpose of this study is to compare the auditory function of patients with type 2 diabetes mellitus with healthy subjects. Furthermore, an attempt was made to relate abnormal brain stem evoked responses with sex, duration of disease, and peripheral sensori-motor polyneuropathy.

\section{METHODS AND MATERIALS}

30 diabetic and 30 healthy subjects gave informed consent to participate in the study, according to the guidelines of the Local Ethics Committee. Patients were re- 
ferred for electro diagnostic test to be screened for diabetic neuropathy by endocrine institute. Thirty healthy individuals from hospital staff were used as the control group. Individuals in both groups were aged 30 to 45 years old. Patients were excluded if they had any record of hearing loss, ear discharge, tinnitus, associated endocrine disorder, for example, myxedema, head injury, neurological deficit, cerebrovascular accident or non safe noise exposure in the past. Patients with a history of drug intake known to cause central neuropathy such as reserpine, alpha methyl dopa, phenytoin or nitrofurantoin, were also excluded from this study.

Diabetic patients were classified according to the duration of the disease in two groups ( $>10$ years old and $\leq 10$ years old). Fasting blood sugar (FBS) and HbAlc were calculated in diabetic patients. To diagnose the diabetic peripheral sensori-motor polyneuropathy in diabetic patients, they underwent nerve conducting study including peroneal, sural, median, and ulnar nerves by electromayography test (Shawrzer tapes made in Germany) with the first author of the article.

For all participants, otoscopy (Reister model 2005Germany) and conventional pure-tone audiometry (PTA) were performed for each ear in a sound-proof room using a clinical audiometer (Interacoustic AC40-Denmark) with TDH-49 earphones at speech frequencies between 250 and $8000 \mathrm{~Hz}(250,500,1000,2000,4000,8000 \mathrm{~Hz})$. The threshold of pure-tone at any frequency $>20 \mathrm{dBHL}$ was defined as hearing loss.

Then ABER responses were recorded using disk shape $\mathrm{Ag}-\mathrm{Ag} \mathrm{Cl}$ electrodes placed on the mastoids and high forehead. The responses were recorded using $80 \mathrm{nHL}$ at a rate of 21.1 click/Sec using $1 \mathrm{mV}$ sensitivity, $10 \mathrm{mV}$ gain and $30-3000 \mathrm{HZ}$ filters. After 2048 stimuli the average response was reproduced [10]. The latency of waves I, III, Vas well as the interwave latencies of I-III, III-V, I-V were identified. Mean and standard deviation (SD) of all parameters were calculated for each group. Besides comparison of ABER parameters between diabetics and healthy people, their relation to the presence or absence of peripheral sensori-motor polyneuropathy, sex, and duration of diabetes $(>10$ years and $\leq 10$ years) were assessed.

\section{Statistical Analysis}

Statistical analysis was performed implementing independent $t$ test, by applying SPSS software version 11.5. Differences were considered significant when $\mathrm{P}$ values were $<0.05$.

\section{RESULTS}

In diabetics, the mean age was $44.7 \pm 6.5,43 \%$ males and $57 \%$ females. Time elapsed since diagnosis of diabetes was $7.2 \pm 5.4$ years. Fasting blood glucose and HbA1c were $(137 \pm 4.5)$ and $(6.4 \% \pm 0.3 \%)$ respectively. Diabetic peripheral sensori-motor polyneuropathy in extremities was diagnosed in 15 out of 30 subjects. In other groups, the mean age was $43.5 \pm 3.1,53 \%$ males and $47 \%$ females, and FBS was $90 \pm 2.8$.

Since there were no significant statistical differences between the findings of both ears, we used the mean results of right and left ears for each measurement in the tables.

\subsection{Pure-Tone Audiometry}

In PTA, the hearing thresholds at 2, 4, $8 \mathrm{KHz}$ were significantly higher in diabetics than healthy subjects, but were in normal range (Table 1).

\subsection{Auditory Brainstem Response}

ABER revealed that absolute latencies of waves I, III, V and interwave latencies of III-V, I-V, I-III were significantly prolonged in the study group when compared to the control subjects $(\mathrm{P}<0.05)$ (Table 2$)$. In the diabetic group, there was no significant statistical difference in I, III, V latencies and I-III, III-V, I-V interwave latencies between patients with the history of more then 10 years of diabetes or fewer $(\mathrm{P}>0.05)$ (Table 3). There was no significant statistical difference in absolute latency \& interwave latencies $(\mathrm{P}>0.05)$ in diabetic subjects with or without peripheral sensori-motor polyneuropathy (Table 4). In both diabetic \& control groups, there were no significant statistical differences between absolute latencies $\&$ interwave latencies between men and women $(\mathrm{P}>$ $0.05)$.

\section{DISCUSSION}

In this study, patients with type 2 diabetes, in conventional PTA (ranging from 250 to $8000 \mathrm{~Hz}$ ) had normal hearing thresholds being consistent with theresults of the findings of Dalton et al. [3]. In contrast, Díaz de LeónMorales LV et al. mentioned that the hearing threshold of people with type 2 diabetes at $8000 \mathrm{~Hz}$ was higher than healthy people [7].

In this study, $50 \%$ of diabetic patients had hearing defects in ABER test despite the normal hearing threshold and good metabolic control (HbAlc $6.4 \pm 0.3)$, in such a way that the latency of waves I, III, V and inter wave latencies of I-III, III-V, I-V in the diabetic group compared to the non-diabetic group were significantly higher (Table 2).

According to a normal hearing threshold in diabetic patients, delayed wave I could be due to reduced nerve 
Table 1. Pure-tone audiometry level (dBSPL) in diabetics and non-diabetics.

\begin{tabular}{cccc}
\hline $\begin{array}{c}\text { Frequencies } \\
(\mathrm{Hz})\end{array}$ & $\begin{array}{c}\text { Hearing threshold } \\
\text { in diabetics } \\
(\text { Mean } \pm \mathrm{SD})\end{array}$ & $\begin{array}{c}\text { Hearing threshold } \\
\text { in nondiabetics } \\
\text { (Mean } \pm \text { SD) }\end{array}$ & PV \\
\hline 250 & $4.08 \pm 3.39$ & $3.91 \pm 3.22$ & 0.85 \\
500 & $4.41 \pm 3.31$ & $4.66 \pm 3.38$ & 0.41 \\
1000 & $4.58 \pm 4.04$ & $2.83 \pm 2.98$ & 0.17 \\
2000 & $5.74 \pm 4.29$ & $2.33 \pm 2.69$ & 0.001 \\
4000 & $8.33 \pm 4.48$ & $4.41 \pm 3.17$ & 0.002 \\
8000 & $10.16 \pm 6.28$ & $6.50 \pm 4.32$ & 0.001 \\
\hline
\end{tabular}

Table 2. Latency of waves I, III, V and interwave latency of waves III-V, I-V, I-III in diabetics and non-diabetics.

\begin{tabular}{ccc}
\hline ABER latencies $(\mathrm{ms})$ & $\begin{array}{c}\text { Diabetics } \\
(\text { Mean } \pm \text { SD) }\end{array}$ & $\begin{array}{c}\text { Non diabetics } \\
(\text { Mean } \pm \text { SD) }\end{array}$ \\
\hline wave I & $1.69 \pm 0.08$ & $1.62 \pm 0.02$ \\
wave III & $3.74 \pm 0.11$ & $3.64 \pm 0.03$ \\
wave V & $5.97 \pm 0.13$ & $5.63 \pm 0.10$ \\
I-III & $2.04 \pm 0.48$ & $2.01 \pm 0.19$ \\
III-V & $2.24 \pm 0.14$ & $2.00 \pm 0.25$ \\
I-V & $4.27 \pm 0.66$ & $4.02 \pm 0.04$ \\
\hline
\end{tabular}

Table 3. Latency of waves I, III, V and interwave latency of waves III-V, I-V, I-III in diabetics based on the duration of diabetes $(\leq 10 \mathrm{y}$ or $>10 \mathrm{y})$.

\begin{tabular}{ccc}
\hline ABER latencies (ms) & Duration $\leq 10 \mathrm{y}$ & Duration $>10 \mathrm{y}$ \\
\hline wave I & $1.67 \pm 0.08$ & $1.72 \pm 0.06$ \\
wave III & $3.68 \pm 0.12$ & $3.77 \pm 0.10$ \\
wave V & $5.96 \pm 0.12$ & $5.98 \pm 0.10$ \\
I-III & $2.02 \pm 0.07$ & $2.05 \pm 0.07$ \\
III-V & $2.23 \pm 0.11$ & $2.23 \pm 0.15$ \\
I-V & $4.22 \pm 0.10$ & $4.29 \pm 0.12$ \\
\hline
\end{tabular}

Table 4. Latency of waves I, III, V and interwave latency of waves III-V, I-V, I-III of diabetics according to the presence or absence of diabetic sensori-motor polyneuropathy.

\begin{tabular}{ccc}
\hline ABER latencies (ms) & $\begin{array}{c}\text { Without peripheral } \\
\text { neuropathy }\end{array}$ & $\begin{array}{c}\text { With peripheral } \\
\text { neuropathy }\end{array}$ \\
\hline wave I & $1.67 \pm 0.07$ & $1.72 \pm 0.07$ \\
wave III & $3.70 \pm 0.11$ & $3.76 \pm 0.10$ \\
wave V & $5.95 \pm 0.12$ & $5.99 \pm 0.12$ \\
I-III & $2.04 \pm 0.06$ & $2.04 \pm 0.06$ \\
III-V & $2.21 \pm 0.13$ & $2.25 \pm 0.15$ \\
I-V & $4.26 \pm 0.11$ & $4.28 \pm 0.13$ \\
\hline
\end{tabular}

conduction velocity in the auditory nerve that occurred secondary to diabetic neuropathy. Prolonged inter wave latencies of I-III, III-V, I-V explains retrocochlear and brain stem involvement [9]. In some articles, the latencies of waves I, III, V and interwave latencies of I-III, III-V, I-V were longer in diabetics than healthy people [1, 9,11]. Bayazit et al. (2000), in 59 diabetic patients, showed a lengthening of the latencies of the main components of the brainstem responses, suggesting microangiopathy [9]. However, our findings do not support his theory. It seems brain stem responses are independent of diabetic microangiopathic complications, such as nephropathy, retinopathy or sensori-motor polyneuropathy. Another explanation for the auditory impairment could be a metabolic compromise. The high metabolic demands of the inner ear and the auditory pathway could make them a target of the disease, even before evidence of other micro vascular complications [7]. Duration of diabetes was not associated with waves' latency or interweave latency (Table 3) and several studies have had similar findings $[6,12]$. Although the wave latencies were associated with the duration of diabetes in articles 1,2 , in this article, the results showed no significant differences between diabetic patients with or without peripheral sensori-motor polyneuropathy (Table 4). This was consistent with the findings of the two articles [2,7]. However, ABER parameters were longer in patients with diabetic sensori-motor polyneuropathy than those without such complications in the research carried conducted by Sharma R and Bayazit Y [1,9]. In this paper,the hearing was evaluated in patients with type 2 diabetes. Similar studies have been conducted on type 1 diabetes $[1,6,9,12]$. It seems that regardless of the type of diabetes, it can lead to hearing problems at brain stem level. Early detection of hearing loss in diabetics, regardless of its causes, has great importance since these patients are-give multiple antibiotics for various reasons,such as diabetic foot ulcers. Antibiotics with mild ototoxic effects may cause profound hearing loss in patients with mild underlying hearing problems [13]. Early awareness of hearing loss, before its clinical manifestation, may be useful. ABER test could be a complementary tool for periodic examination of diabetics.

\section{SUGGESTIONS}

To use ABER as a predictive or diagnostic test for diabetes complications, more and more researches need to be carried out. Different findings mentioned about the results of this test in patients with diabetes could be due to differences in testing methods,stimulation intensity and frequency. Therefore,the standard method of ABER testing would be greatly instrumental. 


\section{ACKNOWLEDGEMENTS}

The authors thank Mr Hosein Zamani for English editing.

\section{REFERENCES}

[1] Sharma, R., Gupta, S.C., Tyagi, I., Kumar, S. and Mukherjee, K. (2000) Brain stem evoked responses in patients with diabetes mellitus. Indian Journal of Otolaryngology and Head \& Neck Surgery, 52, 223-229.

[2] Ferrer, J.P., Biurrun, O., Lorente, J., Conget, J.I., de España, R., Esmatjes, E. and Gomis, R. (1991) Auditory function in young patients with type 1 diabetes mellitus. Diabetes Research and Clinical Practice, 11, 17-22. doi:10.1016/0168-8227(91)90136-2

[3] Dalton, D.S., Cruickshanks, K.J., Klein, R., Klein, B.E. and Wiley, T.L. (1998) Association of NIDDM and hearing loss. Diabetes Care, 21, 1540-1544. doi:10.2337/diacare.21.9.1540

[4] Sieger, A., White, N.H., Skinner, M.W. and Spector, G.J. (1983) Auditory function in children with diabetes mellitus. Annals of Otology, Rhinology \& Laryngology, 92, 237-241.

[5] Chiappa, K.H. (1997) Evoked potentials in clinical medicine. Raven Press, New York, 145-147.

[6] Donald, M.W., Bird, C.E., Lawson, J.S., Letemendia, F.J., Monga, T.N., Surridge, D.H., et al. (1981) Delayed auditory brainstem responses in diabetes mellitus. Journal of Neurology, Neurosurgery \& Psychiatry, 44, 641-644. doi:10.1136/jnnp.44.7.641

[7] Díaz de León-Morales, L.V., Jáuregui-Renaud, K., Ga-
ray-Sevilla, M.E., Hernández-Prado, J. and MalacaraHernández, J.M. (2005) Auditory impairment in patients with type 2 diabetes mellitus. Archives of Medical Research, 36, 507-510. doi:10.1016/j.arcmed.2005.02.002

[8] Akinci, A., Deda, G., Karagöl, U. and Teziç, T. (1994) Brainstem auditory evoked potential, visual evoked potential and nerve conduction velocity and their relation with $\mathrm{HbA} 1 \mathrm{c}$ and beta 2 microglobulin in children with insulin dependent diabetes mellitus. The Turkish Journal of Pediatrics, 36, 279-287.

[9] Bayazit, Y., Yilmaz, M., Kepekçi, Y., Mumbuç, S. and Kanlikama, M. (2000) Use of the auditory brainstem response testing in the clinical evaluation of the patients with diabetes mellitus. Journal of the Neurological Sciences, 181, 29-32.

[10] Hall, J.W. (2007) New handbook of auditory evoked responses. Pearson Education, Boston, 171-211.

[11] Durmus, C., Yetiser, S. and Durmus, O. (2004) Auditory brainstem evoked responses in insulin-dependent (ID) and non-insulin-dependent (NID) diabetic subjects with normal hearing. International Journal of Audiology, 43, 29-33. doi:10.1080/14992020400050005

[12] Konrad-Martin, D., Austin, D.F., Griest, S., McMillan, G.P., McDermott, D. and Fausti, S. (2010) Diabetes-related changes in auditory brainstem responses. Laryngoscope, 120, 150-158. doi:10.1002/lary.20636

[13] Virtaniemi, J., Laakso, M., Kärjä, J., Nuutinen, J. and Karjalainen, S. (1993) Auditory brainstem latencies in type I (insulin-dependent) diabetic patients. American Journal of Otolaryngology, 14, 413-418. doi:10.1016/0196-0709(93)90116-O 